\title{
Patients with posttraumatic stress disorder exhibit an altered phenotype of regulatory $T$ cells
}

Mladen Jergović ${ }^{1,5^{*}}$, Krešo Bendelja $^{1}$, Anđelko Vidović ${ }^{2}$, Ana Savić ${ }^{1}, V^{2}$ alerija Vojvoda', Neda Aberle ${ }^{3}$, Sabina Rabatić ${ }^{5}$, Tanja Jovanovic ${ }^{4}$ and Ante Sabioncello ${ }^{5}$

\begin{abstract}
Background: Regulatory T cells (Tregs) play a key role in immune homeostasis in vivo. Tregs have a critical role in preventing the development of autoimmune diseases and defects in Treg function are implicated in various autoimmune disorders. Individuals with posttraumatic stress disorder (PTSD) have higher prevalence of autoimmune disorders than the general population. We hypothesized that war veterans with PTSD would exhibit a decreased number and/or altered phenotype of Tregs.
\end{abstract}

Methods: We analyzed peripheral blood mononuclear cells (PBMCs) of patients with PTSD ( $N=21)$ (mean age $=45.9)$ and age-matched healthy controls $(N=23)$ (mean age $=45.7)$ to determine the proportion of Tregs and their phenotype according to the expression of CD127 and HLA-DR markers which describe the differentiation stages of Tregs. In addition, we analyzed the expression of membrane ectoenzyme CD39 on Tregs of the study groups, an important component of the suppressive machinery of Tregs.

Results: We found no differences in the proportion of Tregs between PTSD patients and controls, but PTSD patients had a higher percentage of CD127-HLA-DR ${ }^{-}$Tregs and a lower percentage of CD127 ${ }^{\circ} \mathrm{HLA}-\mathrm{DR}{ }^{+}$Tregs compared to controls. There was no difference in expression of CD39 on Tregs of the study groups.

Conclusions: Although the proportions of Tregs in PTSD patients were unchanged, we found that they exhibit a different phenotype of Tregs that might be less suppressive. Impaired differentiation and function of Tregs is likely involved in disruption of immune homeostasis in PTSD.

Keywords: Posttraumatic stress disorder, Regulatory T cells, Autoimmunity

\section{Background}

Regulatory $\mathrm{T}$ cells (Tregs) play a major role in maintaining homeostasis of the immune system by restraining the activity of effector cells and auto-reactive $\mathrm{T}$ lymphocytes, thus controlling immune reactivity. Tregs were first described in 1995 as a subset of $\mathrm{CD} 4^{+} \mathrm{T}$ cells expressing high levels of the interleukin (IL)-2 receptor alpha-chain (CD25) whose depletion led to development of autoimmune diseases [1]. Since CD25 is also expressed by antigen experienced and recently activated effector $\mathrm{T}$ cells, identification of transcription factor forkhead box P3 (FOXP3) as a specific intracellular marker of Tregs, has

\footnotetext{
*Correspondence: mjergovi@unizg.hr

${ }^{1}$ Centre for research and knowledge transfer in biotechnology, University of Zagreb, Zagreb, Croatia

${ }^{5}$ Department for Cellular Immunology, Institute of Immunology,

Rockfellerova ulica 10, Zagreb, Croatia

Full list of author information is available at the end of the article
}

vastly improved the identification of this subpopulation of $\mathrm{T}$ cells $[2,3]$. X-chromosome encoded transcription factor FOXP3 is necessary for the development and function of Tregs and humans with mutation leading to loss of function in the FOXP3 gene develop a fatal lymphoproliferative autoimmune disorder, IPEX (immune dysregulation, polyendocrinopathy, enteropathy, X-linked) [4,5]. Although expressed predominantly by Tregs, FOXP3 is not an exclusive marker of Tregs [6] as it is induced during T-cell receptor (TCR) stimulation in conventional $\mathrm{CD} 4^{+}$ T cells. Other markers such as low levels or lack of expression of IL-7 receptor CD127 have been suggested as useful in identifying peripheral Tregs [7].

Human $\mathrm{T}$ cells with regulatory function contain other FOXP3 $^{-}$subpopulations (Th3, $\mathrm{Tr} 1, \mathrm{i} \mathrm{Tr} 35$, and $\mathrm{CD} 8^{+} \mathrm{CD} 28^{-}$) but $\mathrm{CD} 44^{+} \mathrm{CD} 25^{\text {hi }} \mathrm{FOXP}^{+}$are the most studied and comprehended in the context of homeostasis and autoimmunity 
in humans [8]. Studies of frequency of Tregs in autoimmune diseases such as rheumatoid arthritis, multiple sclerosis and psoriasis yielded conflicting results with systemic lupus erythematosus being the only autoimmune disease showing a consistent decrease of Tregs in the periphery [9]. However functional defects of Tregs have been observed in different human autoimmune diseases [10].

Expression of some surface receptors discriminates between functionally distinct Treg populations. HLA-DR is expressed on terminally differentiated Tregs which are more suppressive than the HLA-DR ${ }^{-}$subset [11]. CD127 discriminates between human regulatory and activated $\mathrm{T}$ cells [12] and frequency of CD127 expressing cells within the FOXP3 ${ }^{+}$population correlates with poor Treg function [13]. CD39 is an ectoenzyme that degrades adenosine triphosphate (ATP) to adenosine monophosphate (AMP). It is expressed by some Tregs and conveys suppression by hydrolyzing extracellular ATP released by damaged cells [14]. CD39 ${ }^{+}$Tregs have the capability of suppressing IL-17 production and are impaired in multiple sclerosis [15].

Posttraumatic stress disorder (PTSD) is a traumarelated disorder that may develop after exposure to one or more traumatic events [16] and is characterized by recurring flashbacks, avoidance of memories of the event, emotional numbing, and hyperarousal. It is estimated that lifetime prevalence of PTSD in the general population is $6.8-8 \%[17,18]$ but combat veterans or individuals exposed to war have a higher risk of developing PTSD with reported prevalence rates ranging between $1.4 \%$ and $31 \%$ [19]. PTSD is associated with various biological and behavioral changes that constitute a higher risk for developing somatic illness [20] and higher mortality rates, especially from heart disease [21]. Several autoimmune or inflammatory disorders have been linked to PTSD, most notably rheumatoid arthritis [22], psoriasis and thyroid disease [23].

Studies of the immune system in PTSD have yielded conflicting results, with increased levels of pro-inflammatory cytokines (IL-1 $\beta$, IL- 6 and tumor necrosis factor (TNF)- $\alpha$ ), lower total $\mathrm{T}$ cells counts, and increased reactivity to antigen skin tests being the most consistent findings [24,25]. Only one study has investigated Tregs in PTSD [26] finding decreased number of Tregs in blood of PTSD patients. Another study [27] showed a decreased number of Tregs in the peripheral blood of human subjects after an acute laboratory stressor. Studies in mice showed that chronic psychosocial stress induced a reduction of regulatory $\mathrm{T}$ cells in peripheral lymph nodes, accompanied by increased T cell effector functions [28].

We hypothesized that war veterans with PTSD would exhibit a decreased number and/or altered phenotype of Tregs. In addition to determining percentages of total Tregs $\left(\mathrm{CD}^{+} \mathrm{CD}^{+}{ }^{+} \mathrm{CD} 25^{+} \mathrm{FOXP}^{+}\right)$in peripheral blood of
PTSD patients, we further characterized Tregs according to their expression of HLA-DR, CD127 and CD39 to investigate whether PTSD patients exhibit a different phenotype of Tregs (possibly functionally distinct) compared to healthy controls.

\section{Methods \\ Subjects}

PTSD patients $(n=25)$ were Croatian male combat veterans, recruited among outpatients at General hospital “dr. Josip Benčević”, Slavonski Brod, Croatia who volunteered to participate in the study. All patients met the ICD-10 [29] PTSD criteria, the official classification in Croatian psychiatric practice. Healthy controls $(n=25)$ were men matched for age and demographics. The study was approved by the Ethic Committee of the hospital and written informed consent was obtained from all subjects.

Prior to phlebotomy, all study participants were examined by an experienced clinician (a psychiatrist), and medical history data relevant to the purpose of this study were recorded. The subjects were then asked to complete rating scales for PTSD, depression and anxiety symptoms.

The level of PTSD symptoms was assessed with the Los Angeles Symptom Checklist (LASC) [30] a self-report measure of PTSD and associated features. We used the 43-item version of the LASC to assess PTSD. Respondents rated the extent to which specific symptoms were a problem for them, using a 5-point scale ranging from 0 (no problem) to 4 (extreme problem). The diagnosis of PTSD was confirmed in all patients, i.e. out of 17 diagnostic items they reported (with a rating of four) at least one item assessing reexperiencing of the trauma, three items indexing avoidance and numbing, and two items reflecting increased arousal. Depression symptoms were assessed with the Beck Depression Inventory (BDI) [31] and current anxiety level (state anxiety) was determined by the corresponding part of Spielberger State-Trait Anxiety Inventory (STAI) [32].

Healthy controls did not meet lifetime or current criteria for any psychiatric disorder and had no symptoms or signs of current psychiatric disease. Due to ethical considerations the PTSD patients did not discontinue their regular medications. Standard laboratory tests were also performed in all participants. Two PTSD patients were excluded from the analysis because of high levels of CRP (>10 mg/L) indicating acute inflammation or infection. Another two PTSD patient were excluded because of chronic illness (multiple sclerosis and diabetes) and two controls were excluded due to very young age (more than 20 years below the group average). At the time of sampling, all other study subjects had no symptoms or signs of acute or chronic physical illness. None of the included participants reported intake of glucocorticoids. 
Due to the ethical considerations, the majority of patients $(n=17)$ were medicated at the time of the study. They were taking selective serotonin reuptake inhibitors (SSRIs) $(n=12)$, benzodiazepines $(n=15)$, or antipsychotics (as an augmentation therapy, $\mathrm{n}=8$ ).

\section{Blood sampling and lymphocyte phenotyping}

We collected fasting whole blood by venipuncture from 25 PTSD patients and 25 healthy controls on the same day between 7 and 9 AM. Blood was collected in sodium heparin treated tubes and serum tubes (BD Biosciences, Heidelberg, Germany). Serum tubes were sent to the hospital laboratory for measurement of C-reactive protein (CRP) levels to test for the presence of acute inflammation. Determination of CRP was performed using a standard latex immunoassay; CRP Vario (Abbott Diagnostics, Lake Forest, USA). Absolute numbers of lymphocytes were determined from whole blood using TruCOUNT ${ }^{\mathrm{mm}}$ Tubes (BD Biosciences). $50 \mu \mathrm{L}$ of whole blood was incubated for 15 minutes with fluorescein isothiocyanate (FITC)-conjugated anti-CD45 (clone 2D1) and phycoerythrin ( $\mathrm{PE})$-conjugated anti-CD14 ( $\mathrm{M} \phi \mathrm{P} 9)$ (BD Biosciences) antibodies at room temperature, then treated with $450 \mu \mathrm{l}$ of lysing buffer (BD Biosciences) for 10 minutes before flow cytometry was performed.

Peripheral blood mononouclear cells (PBMCs) were isolated on Ficoll-Paque ${ }^{\text {Tm }}$ gradient (GE Healthcare Life Sciences, Uppsala, Sweden). Upon separation, mononuclear cells were washed, resuspended in freezing medium (10\% FCS, 10\% DMSO, 80\% RPMI 1640) and transferred within a Freezing Container (Sigma-Aldrich, St. Louis, USA) to $-80^{\circ} \mathrm{C}$ overnight, then stored in liquid nitrogen until further processing.. However, this was not a concern, since $\mathrm{T}$ cell subpopulations have been shown to be well preserved by cryopreservation [33]. Reports of cryopreservation effect on FOXP3 expression are conflicting, but the latest report indicates no effect if a medium with a low concentration of FCS is used [34]. We have tested the impact of the cryopreservation method by measuring Treg frequencies and phenotype in fresh and freeze/ thawed PBMCs of a small random sample $(\mathrm{N}=5)$. Frozen $\mathrm{PBMCs}$ were later quickly thawed in water bath at $37^{\circ} \mathrm{C}$, resuspended in a pre-warmed RPMI 1640 medium and stained with antibodies for phenotypic analysis. For quantification of lymphocyte phenotypes, 500,000 cells were stained with Alexa Fluor 647 (AF 647)-conjugated anti-CD3 (HIT3a), Alexa Fluor 488 (AF 488)-conjugated anti-CD56 (HCD56), AF 488-conjugated anti-CD16 (3G8), PE-conjugated anti-CD19 (HIB19), peridinin-chlorophyllprotein (PerCP)-conjugated anti-CD8a (HIT8a), and Pacific Blue $^{\text {Tw }}(\mathrm{PB})$-conjugated anti-CD4 (RPA.T4) (Biolegend, San Diego, USA). Following antibody staining, samples were washed in a staining buffer and at least 20,000 cells were collected in the lymphocyte gate. Matching isotype controls were used for setting positivity gates: AF 647conjugated mouse IgG2a, AF 488-conjugated mouse IgG1 kappa, PE-conjugated mouse IgG1 kappa, PerCP-conjugated mouse IgG1 kappa, PB-conjugated mouse IgG1 kappa (Biolegend).

For quantification and phenotyping of Tregs 500,000 cells were stained with PB-conjugated anti-CD4, FITCconjugated anti-CD25 (BC96), allophycocyanin (APC)/ cyanine 7 (Cy7)-conjugated anti-CD3(HIT3a), PerCPconjugated anti-HLA-DR (L243), AF 647-conjugated antiCD127 (HCD127) (Biolegend) and PE-CY7-conjugated anti-CD39 (Ebioscience, San Diego, USA). After incubation in the dark for 15 minutes, cells were washed and fixed. The cells were then washed in a permeabilization buffer and stained with PE anti-human FOXP3 Staining Set (Ebioscience) following manufacturer instructions. Following antibody staining, samples were washed in the permeabilization buffer and at least 50,000 cells in the lymphocyte gate were collected. The isotype controls used for setting positivity gates were as follows: PB-conjugated mouse IgG1 kappa, FITC-conjugated mouse IgG1, kappa, APC/Cy7-conjugated mouse IgG2a kappa, PerCP-conjugated mouse IgG2a kappa, AF-conjugated 647 mouse IgG1 kappa (Biolegend) and PE-CY7-conjugated mouse IgG 1 kappa (Ebioscience). The gating strategy we used for identification and phenotypic characterization of Tregs is depicted in Figure 1. All samples were run on an LSRII flow cytometer (BD Biosciences) and data were analyzed with FlowJo software (Tree Star, Ashland, USA).

\section{Statistical analyses}

Participants' demographic characteristics with categorical data were compared using Fisher exact test for a $2 \times 2$ contingency table (vassarstats.net/tbl2x2.html). Distribution normality for all continuous variables was assessed per group by visual inspection of the data (shape and symmetry of distribution, outliers, P-P plot) and by ShapiroWilk's $W$-test, performed with Statistica, v 6 (StatSoft Inc., Tulsa, USA). The effect of cryopreservation was assessed by comparing Treg frequencies and phenotype of the same subjects before and after cryopreservation with paired samples $T$ test. Since the distribution of several variables was typically skewed, we used a nonparametric resampling procedure with 5,000 replications obtained from the complete study sample for all variables and tests applied. Descriptive statistics and effect sizes (Cohen's d) with respective confidence intervals (CIs) were calculated from the original dataset using bootstrap (resampling with replacement) methods. Statistical inferences were verified by randomization (resampling without replacement) test. All sampling and computation was programmed using extended Resampling Stats language and run by Statistics 101, v 2.8 resampling statistics software (http://www. statistics101.net). Results are presented as means (an 

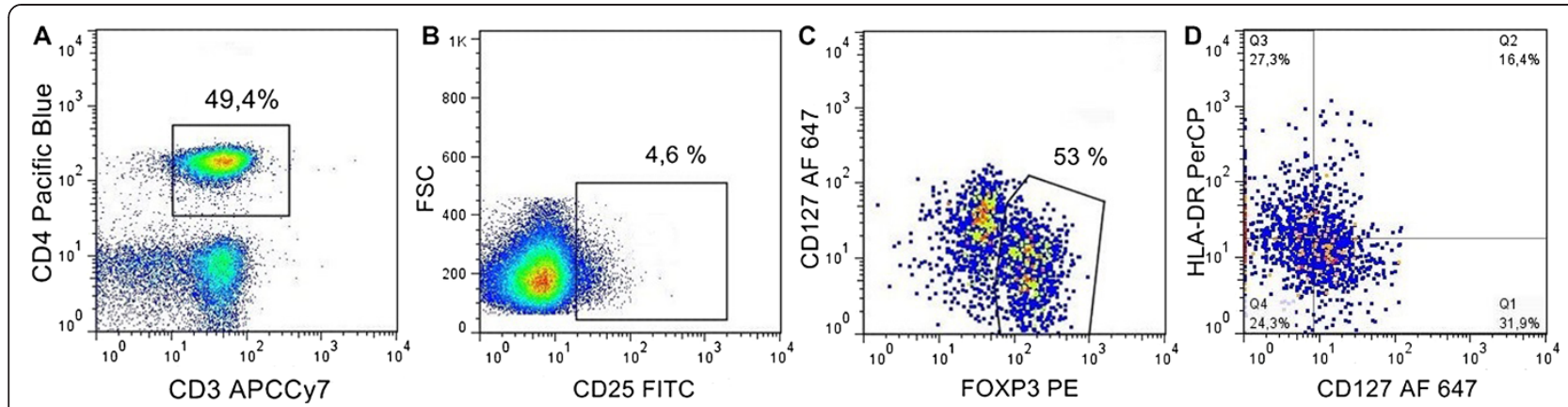

Figure 1 Gating strategy for identification of Tregs populations. Upon gating on $\mathrm{CD}^{+} \mathrm{CD} 4^{+}$cells $(\mathbf{A})$ a small percentage of cells with the highest expression of CD25 was gated (B) among these CD25 hi cells two distinct populations according to expression of FOXP3 and CD127 markers were visible (C). Tregs were identified as FOXP3 ${ }^{+} \mathrm{CD} 127^{\mathrm{lo} /-}$ subpopulation and divided into four subpopulations according to expression of HLA-DR and CD127 (D).

estimate of population mean based on 5,000 bootstrap samples) $\pm S D$ of the sampling distribution (the estimate of the sample $S E$ ) and effect sizes (ES, Cohen's d) with associated 95\% confidence intervals (CI). Two-tailed p-values were obtained as a proportion of the sampling distribution of absolute differences between 5,000 randomized group means (test statistic of interest) that are at least as extreme as the difference between original groups mean. Psychometric test scores (four LASC variables, one BDI and one STAI-S variable) and phenotype variables (nine variables) were correlated by using Spearman's rank order correlations.

\section{Results}

\section{Characteristics of participants}

As shown in Table 1, the groups did not differ in respect of age, marital status, smoking habit and alcohol consumption. PTSD patients were slightly less educated, and a substantial proportion of this group was retired or unemployed. The patient group had higher scores in all psychometric tests with higher frequency and intensity of PTSD symptoms as well as higher levels of depression and anxiety symptoms. Although there are reports of low-grade inflammation determined by elevation of Creactive protein in PTSD patients $[35,36]$, we found no difference in CRP levels between groups (Table 1).

\section{Lymphocyte phenotyping}

We have calculated and presented results of both hypothesis testing and the effect sizes of the difference in phenotypic variables between PTSD patients and healthy controls.

PTSD patients and healthy controls did not differ with respect to absolute numbers of lymphocytes (PTSD: $2444,4 \pm 144,7 \mathrm{cells} / \mu \mathrm{l}$; controls: $2719,8 \pm 115,6, \mathrm{p}=0.13$, $\mathrm{ES}=-0.11,95 \% \mathrm{CI}[-0.28,0.03])$, but PTSD patients had significantly higher proportions of cytotoxic $\mathrm{T}$ cells
$\left(\mathrm{CD}^{+} \mathrm{CD}^{+}\right)$(PTSD: $27.5 \pm 1.94 \%$, controls: $20.9 \pm 1.52 \%$, $\mathrm{p}=0.011 ; \mathrm{ES}=0.17[0.05,0.31]), \mathrm{B}\left(\mathrm{CD}^{-} \mathrm{CD} 19^{+}\right)(\mathrm{PTSD}:$ $5.7 \pm 0.5 \%$, controls: $2.7 \pm 0.3 \%, p<0.001$; ES $=0.27$ [0.18, 0.39 ] and NK cells $\left(\mathrm{CD}^{-} \mathrm{CD}^{-} 6^{+} \mathrm{CD} 56^{+}\right)$(PTSD: $15.8 \pm$ 2.5\%, controls: $8.5 \pm 0.7 \%, \mathrm{p}<0.01$ : $\mathrm{ES}=0.15[0.08,0.22]$ ). Results obtained for total $\mathrm{T}\left(\mathrm{CD}^{+}\right)$, helper $\mathrm{T}\left(\mathrm{CD}^{+} \mathrm{CD}^{+}\right)$ cells, and their subpopulations, primarily Tregs subsets, are shown in Figure 2. PTSD patients had a significantly lower percentage of $\mathrm{CD}^{+}(\mathrm{ES}=-0.28[-0.37,-0.19])$ and $\mathrm{CD}^{+} \mathrm{CD}^{+}(\mathrm{ES}=-0.51[-0.74,-0.33])$ cells compared to healthy controls. Upon gating on $\mathrm{CD} 4^{+} \mathrm{CD} 25^{\mathrm{hi}}$ cells (Figure 1b), two populations were observed based on expression of FOXP3 and CD127 markers. We identified Tregs as a distinct population of $\mathrm{CD} 3{ }^{+} \mathrm{CD} 44^{+} \mathrm{CD} 25^{+} \mathrm{FOXP} 3^{+}$ $\mathrm{CD} 127^{\mathrm{lo} /}$ cells (Figure 1c) and further analyzed expression of CD39 and HLA-DR markers on these cells (Figure 1d). As shown in Figure 2, there was no difference in the number of Tregs $(E S=-0.01[-0.07,0.06])$ but PTSD patients had a higher percentage of CD127-HLA-DR ${ }^{-}$ Tregs $(E S=0.17[0.05,0.29])$ and a lower percentage of $\mathrm{CD} 127^{\mathrm{lo}} \mathrm{HLA}-\mathrm{DR}{ }^{+}$Tregs $(\mathrm{E}=-0.17[-0.32,-0.03])$. As shown in Table 2. Cryopreservation method had no effect on Treg numbers and phenotype. Measured frequencies of Tregs in healthy controls and PTSD patients were similar or higher than in previous reports based on whole blood staining [26] further confirming no decrease in FOXP3 levels caused by cryopreservation. No difference in percentages of $\mathrm{CD} 9^{+}$Tregs (out of total Tregs) was observed between study groups $(E=-0.06[-0.19,0.06])$. In addition, we analyzed a subpopulation of recently activated non-regulatory helper $\mathrm{T}$ cells $\left(\mathrm{CD} 4^{+} \mathrm{CD} 25^{+} \mathrm{FOXP} 3^{-}\right.$ HLA-DR ${ }^{+}$) (Figure 2) and found no difference between the study groups $(\mathrm{E}=-0.01[-0.15,0.09])$.

These results suggest that PTSD has a moderate effect (ES between 0.3 and 0.5 ) on total $\mathrm{T}$ and helper $\mathrm{T}$ cells and a small effect (ES between 0.1 and 0.2 ) on $\mathrm{CD} 127^{\mathrm{lo}} \mathrm{HLA}$ $\mathrm{DR}^{+}$and $\mathrm{CD}_{127^{-} \mathrm{HLA}-\mathrm{DR}}^{-}$Tregs, but given that the 
Table 1 Characteristics of participants

\begin{tabular}{|c|c|c|c|}
\hline Variables & PTSD patients $(\mathrm{N}=21)$ & Healthy controls $(\mathrm{N}=23)$ & $\mathbf{p}$ \\
\hline Age, years $^{a}$ & $45.9 \pm 1,02$ & $45.7 \pm 1.64$ & 0.949 \\
\hline Education $^{\text {b }}$ & & & 0.022 \\
\hline Elementary/high & $21(100)$ & $17(74)$ & \\
\hline University & $0(0)$ & $6(26)$ & \\
\hline Marital status ${ }^{\mathrm{b}}$ & & & 0.335 \\
\hline Married & $18(86)$ & $22(96)$ & \\
\hline Single/divorced & $3(14)$ & $1(4)$ & \\
\hline Work status ${ }^{\mathrm{b}}$ & & & $<0.001$ \\
\hline Employed & $1(5)$ & $21(91)$ & \\
\hline Unemployed/retired & $20(95)$ & $2(9)$ & \\
\hline Tobacco use & & & 0.081 \\
\hline Yes & $14(67)$ & $9(39)$ & \\
\hline No & $7(33)$ & $14(61)$ & \\
\hline Alcohol use ${ }^{b}$ & & & 0.125 \\
\hline Yes & $15(71)$ & $21(91)$ & \\
\hline No & $6(29)$ & $2(9)$ & \\
\hline$C R P^{a}, m g / L$ & $2.5 \pm 0.50$ & $2.3 \pm 0.39$ & 0.822 \\
\hline BDI score ${ }^{a}$ & $30.3 \pm 2.36$ & $5.1 \pm 1.18$ & $<0.001$ \\
\hline LASC score ${ }^{a}$ re-experiencing & $8.6 \pm 0.47$ & $1.3 \pm 0.42$ & $<0.001$ \\
\hline Avoidance & $15.0 \pm 1.05$ & $4.4 \pm 0.93$ & $<0.001$ \\
\hline Arousal & $22.5 \pm 1.34$ & $4.8 \pm 1.00$ & $<0.001$ \\
\hline 17-item PTSD index & $46.1 \pm 2.63$ & $10.4 \pm 2.20$ & $<0.001$ \\
\hline 43-item full scale index & $95.5 \pm 5.48$ & $36.0 \pm 2.61$ & $<0.001$ \\
\hline STAI-State ${ }^{a}$, score & $49.0 \pm 1.04$ & $36.0 \pm 2.61$ & 0.001 \\
\hline
\end{tabular}

${ }^{a}$ Data presented as mean (an estimate of population mean based on 5,000 bootstrap samples) $\pm S D$ of the sampling distribution (the estimate of the sample $S E$ ). The associated two-tailed p-values are obtained as proportion of sampling distribution of absolute differences between 5,000 randomized group means that are at least as extreme as the difference between original groups mean.

${ }^{\mathrm{b}}$ Data presented as $\mathrm{n}(\%)$. The associated p-values are Fisher's exact two-tailed probabilities.

associated CIs do not include zero, the effects may have important practical consequences.

\section{Correlations and subgroup analyses}

BDI, STAI-State, and LASC (3 clusters of PTSD symptoms, 17-item PTSD index, 43-item full scale indeks) scores were correlated with phenotype variables in PTSD patients. Out of 54 correlations performed between phenotype variables and psychometric test scores, only two were statistically significant (without corrections for multiple comparisons) -1 ) BDI vs. CD127-HLA-DR ${ }^{-}$ (Spearman $\mathrm{R}=-0.44, \mathrm{p}=0.045$ ), and 2) LASC arousal vs. $\mathrm{CD} 127^{\mathrm{lo}} \mathrm{HLA}^{-D R^{-}}(\mathrm{R}=0.46, \mathrm{p}=0.033)$.

We have also compared all phenotype variables between patients who were taking SSRIs $(n=12)$, benzodiazepines $(n=15)$, or antipsychotics $(n=8)$ and those who were not using medication. The differences were tested using the same nonparametric resampling procedure as described in Statistical analyses section. All $\mathrm{p}$ values were above significance level $(>0.05)$.

\section{Discussion}

Although PTSD patients did not have decreased percentage of Tregs as hypothesized, our study shows an altered phenotype of Tregs in war veterans with PTSD. They had a higher percentage of CD127 HLA-DR ${ }^{-}$Tregs and a lower percentage of CD127 ${ }^{\mathrm{lo}} \mathrm{HLA}-\mathrm{DR}^{+}$Tregs in comparison to healthy controls, suggesting a less suppressive phenotype that could increase susceptibility to autoimmune diseases.

We also observed some changes in major lymphocyte populations. The percentage of circulating $\mathrm{T}$ lymphocytes in PTSD patients was lower in comparison to healthy controls, which has been previously reported in men with a past history of PTSD [37]. However most studies showed no differences [38] or even higher numbers of $\mathrm{T}$ cells [39]. We also found a decreased proportion of circulating helper $\mathrm{T}$ cells as in previous studies $[37,40]$ in contrast to other studies that have found no differences [41] or higher numbers of helper T cells [39]. These contradictory findings can be explained by the 


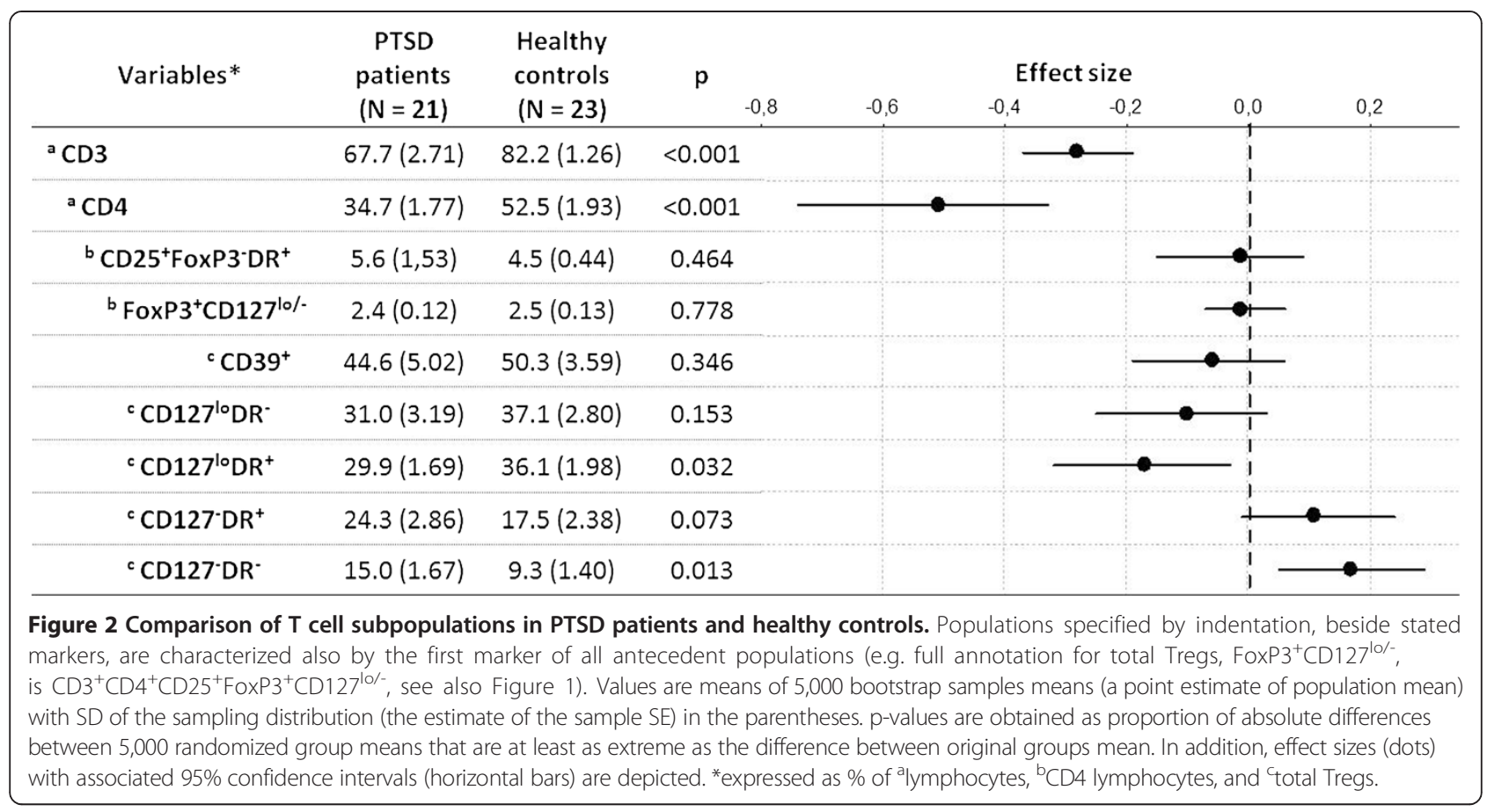

genetic and behavioral heterogeneity among PTSD patients and no conclusions on immune reactivity in PTSD patients should be drawn based on the sheer numbers of $\mathrm{T}$ cell populations. With this in mind our main goal was to examine the proportion and differentiation markers of Tregs in PTSD patients.

Only one previous study [26] examined Tregs in PTSD patients and reported a $48 \%$ reduction of regulatory $\mathrm{T}$ cells $\left(\mathrm{CD}_{4}{ }^{+} \mathrm{CD} 25^{\text {hi }} \mathrm{FOXP}^{+}\right)$in chronic PTSD. We did not replicate the findings of this study as there was no difference in peripheral Tregs between our PTSD group and healthy controls. It is important to note that the inclusion of CD127 marker in our analysis allowed us a more accurate discrimination between Tregs and

Table 2 Effect of cryopreservation on Treg numbers and phenotype

\begin{tabular}{|c|c|c|c|}
\hline & $\begin{array}{l}\text { Fresh PBMCs } \\
\qquad(N=5)\end{array}$ & $\begin{array}{l}\text { Frozen PBMCs } \\
\qquad(\mathrm{N}=5)\end{array}$ & $p$ value \\
\hline $\mathrm{CD}^{+} \mathrm{CD}^{+}$ & 51,4 & 51,38 & 0,99 \\
\hline $\begin{array}{l}\text { Tregs }\left(\mathrm{CD}^{+} \mathrm{CD}^{+} \mathrm{CD}^{+} 5^{+}\right. \\
\left.\mathrm{FOXP}^{+} \mathrm{CD} 127^{\mathrm{lo} /-}\right)\end{array}$ & 2,16 & 2,15 & 0,96 \\
\hline $\mathrm{CD}_{12} 7^{\mathrm{lo}} \mathrm{HLA}^{-D R^{-}}$Tregs & 35,8 & 34,8 & 0,77 \\
\hline $\mathrm{CD} 127^{\mathrm{lo}} \mathrm{HLA} \mathrm{DR}{ }^{+}$Tregs & 35,96 & 37,56 & 0,53 \\
\hline $\mathrm{CD} 127^{-} \mathrm{HLA}^{-D R^{+}}$Tregs & 20,54 & 20,8 & 0,91 \\
\hline $\mathrm{CD} 127^{-} \mathrm{HLA}^{-\mathrm{DR}}{ }^{-}$Tregs & 7,67 & 6,77 & 0,36 \\
\hline
\end{tabular}

The impact of the cryopreservation method was tested by measuring Treg frequencies and phenotype in fresh and freeze/thawed PBMCs of a small random sample $(\mathrm{N}=5)$. Treg frequencies and phenotype of the same subjects before and after cryopreservation were compared with paired samples $T$ test (data represented as group means). The results indicate no effect of cryopreservation on Treg numbers and phenotype. activated T cells. Most of the common markers used to characterize Tregs can also be expressed by activated nonregulatory T cells. Human FOXP3 was found to be transiently expressed in $\mathrm{T}$ cell receptor-stimulated $\mathrm{CD} 4^{+} \mathrm{CD} 25^{-}$ $\mathrm{T}$ cells that do not have regulatory properties [42]. CD127 is constitutively down-regulated on functional human Tregs, while it is highly expressed on effector/memory $\mathrm{T}$ cells although activated non-regulatory $\mathrm{T}$ cells have also been shown to down-regulate CD127 upon activation [43]. Thus we have identified the $\mathrm{CD} 4{ }^{+} \mathrm{CD} 25^{\mathrm{hi}} \mathrm{FOXP}^{+}$ $\mathrm{CD} 127^{\mathrm{lo} /}$ subpopulation of $\mathrm{T}$ cells as the purest in Tregs but we cannot claim that absolutely all activated nonregulatory $\mathrm{T}$ cells were excluded from the analysis. Although there was no difference in Treg levels, we found that PTSD patients display a lower proportion of CD $127^{\text {lo }}$ HLA-DR ${ }^{+}$Tregs and a higher proportion of CD127-HLA-DR $^{-}$Tregs. HLA-DR expression identifies a functionally distinct population of terminally differentiated human Tregs [11]. FOXP3 expression is significantly higher in the HLA-DR ${ }^{+}$Tregs and these cells exhibit earlier kinetics of responder T cells (Tresp) suppression than the HLA-DR ${ }^{-}$subset [10]. The most interesting difference in the Tregs phenotype was the percentage of $\mathrm{CD}^{2} 27^{-} \mathrm{HLA}^{-} \mathrm{DR}^{-}$cells which was significantly higher in PTSD patients (15\%) than in healthy controls (9.3\%). These cells are non-mature Tregs [44] that are less suppressive than HLA-DR expressing cells and were found to be impaired in multiple sclerosis patients. Thus it appears that PTSD patients might exhibit a less suppressive phenotype of peripheral Tregs although further ex vivo analysis of Tresp inhibition is needed to 
confirm this hypothesis. Studies of the immune system in PTSD have produced conflicting results although there is evidence for increased peripheral inflammation manifested by increased levels of pro-inflammatory cytokines (IL-1 $\beta$, IL-6 and TNF- $\alpha$ ) [24,25]. Since multiple mechanisms operate in Treg-mediated suppression, there are various ways through which altered Treg differentiation may contribute to the observed immune changes in PTSD. There are reports of both increased [26] and decresed [45] ex vivo proliferation of polyclonaly stimulated effector $\mathrm{T}$ cells in PTSD patients. Tregs suppress proliferation of other CD4+ and CD8+ T cells when Treg and responder populations are co-cultured and stimulated with specific antigen or a polyclonal TCR stimulator [46]. Therefore, to further examine functional consequences of the observed alterations in Treg phenotype, the distinct Treg subpopulations need to be isolated and cocultured with stimulated Tresp cells, which was beyond the scope of this study. Tregs also produce various cytokines such as IL-10, IL-4, IL-35 and IL-13 which are involved in the suppression of the pro-inflammatory cytokine response $[46,47]$. Additionally, Tregs can steer monocyte differentiation toward alternatively activated macrophages with strong anti-inflammatory potential [48]. Alterations in all of these Treg mechanisms of suppression could potentially contribute to the immunological abnormalities described in PTSD.

Future studies should establish whether the observed changes in the Treg phenotype are due to changes in differentiation and distribution of thymically derived $\mathrm{FOXP}^{+}$regulatory $\mathrm{T}$ cells (tTregs) or induction of peripheral Tregs (pTregs). This is complicated by the lack of specific markers that can distinguish tTregs from pTregs [8]. Thymically derived Tregs were shown to be able to convert to Th17 cells [49] in the presence of IL-6. Since higher levels of IL-6 in PTSD patients have been reported in several studies [24] Tregs conversion to inflammatory Th17 cells is an additional possible mechanism of immune dysregulation that needs to be further studied. Glucocorticoids inhibit the ability of antigen presenting cells to stimulate effector T lymphocytes and favor Tregs cell induction [50]. In a previous study our group has shown that lymphocytes isolated from PTSD patients exhibited decreased intracellular glucocorticoid receptor (GCR) levels compared with controls [51], thus signaling through GCRs is a way that neuroendocrine alterations in PTSD could affect Tregs differentiation and function. Defects of Tregs differentiation and function are likely involved in chronic inflammation implicated in PTSD and higher prevalence of autoimmune disorders observed in PTSD patients.

One of the limitations of the study is that we didn't administer The Clinician-Administered PTSD Scale (CAPS), considered to be the "gold standard" in PTSD assessment
[52]. Instead, a self-report scale (LASC) was used to assess the level of PTSD symptoms. We must emphasize that the PTSD group analyzed in this study consisted of treatment-resistant patients who started their treatment shortly after the war in Croatia. They were assessed on multiple occasions (yearly) with numerous tests including CAPS according to multimodal assessment principles [53]. The severity of their condition was also reflected in the high BDI scores (Table 1). One cannot exclude the possibility that the observed differences in cellular phenotype might have been the result of the comorbid depression in PTSD patients. However, out of all correlations performed between severity of depression symptoms (BDI scores) and phenotype variables, we found only one significant correlation - BDI scores negatively correlated with percentages of $\mathrm{CD}^{2} \mathrm{7}^{-} \mathrm{HLA}^{-} \mathrm{DR}^{-}$cells, i.e. patients with higher levels of depression symptoms tended to have lower percentages of Tregs with this phenotype. On the other hand, this subpopulation was found to be more prevalent in PTSD patients, indicating that PTSD, and not depression, was the more likely basis of this difference.

Another shortcoming of the study is that due to ethical considerations, the majority of patients were medicated at the time of the study. Although additional analyses did not reveal any significant associations of phenotype variables with the type of drug patients were using, this question remains open since the group sizes were too small to draw valid conclusions from these analyses.

\section{Conclusions}

There is ample evidence in the literature for systemic inflammation and deleterious health consequences in PTSD, but the mechanisms of immune dysregulation in PTSD are not well understood. Results of this study indicate that altered differentiation of Tregs might be involved in the disruption of immune homeostasis in chronic stress. Since the prevalence of PTSD is fairly common in the general population and very high in individuals exposed to severe trauma, research on immune systems in PTSD is of great importance for understanding the mechanisms of traumarelated development of somatic disorders and developing future therapeutic interventions.

\section{Abbreviations \\ CRP: C-reactive protein; BDI: Beck Depression Inventory; GCR: Glucocorticoid receptors; LASC: Los Angeles Symptom Checklist; PBMCs: Peripheral blood mononouclear cells; PTSD: Posttraumatic stress disorder; STAl: State-Trait Anxiety Inventory; Tregs: Regulatory T cells; Tresp: Responder T cells.}

\section{Competing interests}

The authors declare that they have no competing interests.

\section{Authors' contributions}

MJ performed laboratory experiments, analysis of flow cytometry data and wrote the first draft of the manuscript. KB, AV, TJ and SR conceived and designed the experiments. AS and W isolated leukocytes and performed the experiments. AS performed statistical analyses of the data and contributed to 
the study design. NA organized and conducted psychological testing and blood sampling. All authors read and approved the final manuscript.

\section{Acknowledgements}

The authors would like to thank the staff of the General hospital "dr. Josip Benčević", Slavonski Brod, Croatia for technical assistance, help with organization of blood drawing and immediate transportation of the samples. This study was financed by a grant from the Ministry of Science, Education and Sports of the Republic of Croatia (021-0212432-2434 to AS).

\section{Author details}

${ }^{1}$ Centre for research and knowledge transfer in biotechnology, University of Zagreb, Zagreb, Croatia. ${ }^{2}$ Department of Psychiatry, University Hospital Dubrava, Zagreb, Croatia. ${ }^{3}$ General hospital "dr. Josip Benčević", Slavonski Brod, Croatia. ${ }^{4}$ Department of Psychiatry \& Behavioral Sciences, Emory University, Atlanta, GA, USA. ${ }^{5}$ Department for Cellular Immunology, Institute of Immunology, Rockfellerova ulica 10, Zagreb, Croatia.

Received: 8 May 2014 Accepted: 7 August 2014

Published: 20 August 2014

\section{References}

1. Sakaguchi S, Sakaguchi N, Asano M, Itoh M, Toda M: Pillars article: immunologic self-tolerance maintained by activated $T$ cells expressing IL-2 receptor a-chains (CD25). Breakdown of a single mechanism of self-tolerance causes various autoimmune diseases. J. Immunol. 1995. J Immunol 2011, 186:3808-3821.

2. Fontenot JD, Gavin MA, Rudensky AY: Foxp3 programs the development and function of CD4 + CD25+ regulatory T cells. Nat Immunol 2003, 4:330-336.

3. Hori S, Nomura T, Sakaguchi S: Control of regulatory T cell development by the transcription factor Foxp3. Science 2003, 299:1057-1061.

4. Chatila TA, Blaeser F, Ho N, Lederman HM, Voulgaropoulos C, Helms C, Bowcock AM: JM2, encoding a fork head - related protein, is mutated in X-linked autoimmunity - allergic disregulation syndrome. J Clin Invest 2000, 106:75-81

5. Bennett CL, Christie J, Ramsdell F, Brunkow ME, Ferguson PJ, Whitesell L, Kelly TE, Saulsbury FT, Chance PF, Ochs HD: The immune dysregulation, polyendocrinopathy, enteropathy, X-linked syndrome (IPEX) is caused by mutations of FOXP3. Nat Genet 2001, 27:20-21.

6. Ziegler SF: FOXP3: of mice and men. Annu Rev Immunol 2006, 24:209-226

7. Liu W, Putnam AL, Xu-Yu Z, Szot GL, Lee MR, Zhu S, Gottlieb PA, Kapranov P, Gingeras TR, Fazekas de St Groth B, Clayberger C, Soper DM, Ziegler SF, Bluestone JA: CD127 expression inversely correlates with FoxP3 and suppressive function of human CD4+ T reg cells. J Exp Med 2006, 203:1701-1711.

8. Povoleri GAM, Scottà C, Nova-Lamperti EA, John S, Lombardi G, Afzali B: Thymic versus induced regulatory $T$ cells - who regulates the regulators? Front Immunol 2013, 4:169.

9. Long SA, Buckner JH: CD4 + FOXP3+ T regulatory cells in human autoimmunity: more than a numbers game. J Immunol 2011 187:2061-2066

10. Costantino CM, Baecher-Allan CM, Hafler DA: Human regulatory T cells and autoimmunity. Eur J Immunol 2009, 38:921-924.

11. Baecher-Allan C, Wolf E, Hafler DA: MHC class II expression identifies functionally distinct human regulatory T cells. J Immunol 2006 176:4622-4631

12. Seddiki N, Santner-Nanan B, Martinson J, Zaunders J, Sasson S, Landay A, Solomon M, Selby W, Alexander SI, Nanan R, Kelleher A, Fazekas de St Groth B: Expression of interleukin (IL)-2 and IL-7 receptors discriminates between human regulatory and activated T cells. J Exp Med 2006, 203:1693-1700.

13. Michel L, Berthelot L, Pettré S, Wiertlewski S, Lefrère F, Braudeau C, Brouard S, Soulillou J, Laplaud D: Patients with relapsing-remitting multiple sclerosis have normal Treg function when cells expressing IL-7 receptor a-chain are excluded from the analysis. J Clin Invest 2008, 118:3411-3419.

14. Borsellino G, Kleinewietfeld M, Di Mitri D, Sternjak A, Diamantini A, Giometto R, Höpner S, Centonze D, Bernardi G, Dell'Acqua ML, Rossini PM, Battistini L, Rötzschke O, Falk K: Expression of ectonucleotidase CD39 by Foxp3+ Treg cells: hydrolysis of extracellular ATP and immune suppression. Blood 2007, 110:1225-1232.
15. Fletcher JM, Lonergan $\mathrm{R}$, Costelloe $\mathrm{L}$, Kinsella $\mathrm{K}$, Moran B, O'Farrelly $\mathrm{C}$, Tubridy N, Mills KHG: CD39 + Foxp3+ regulatory T Cells suppress pathogenic Th17 cells and are impaired in multiple sclerosis. J Immunol 2009, 183:7602-7610.

16. American Psychiatric Association: Diagnostic and Statistical Manual of Mental Disorders. 5th edition. Arlington, VA: American Psychiatric Publishing; 2013.

17. Vieweg WVR, Julius DA, Fernandez A, Beatty-Brooks M, Hettema JM, Pandurangi AK: Posttraumatic stress disorder: clinical features, pathophysiology, and treatment. Am J Med 2006, 119:383-390.

18. Yehuda R, LeDoux J: Response variation following trauma: a translational neuroscience approach to understanding PTSD. Neuron 2007, 56:19-32.

19. Sundin J, Fear NT, Iversen A, Rona RJ, Wessely S: PTSD after deployment to Iraq: conflicting rates, conflicting claims. Psychol Med 2010, 40:367-382.

20. Barrett DH, Doebbeling CC, Schwartz DA, Voelker MD, Falter $\mathrm{KH}$, Woolson RF, Doebbeling BN: Posttraumatic stress disorder and self-reported physical health status among U.S. Military personnel serving during the Gulf War period: a population-based study. Psychosomatics 2002, 43:195-205.

21. Boscarino JA: A prospective study of PTSD and early-age heart disease mortality among Vietnam veterans: implications for surveillance and prevention. Psychosom Med 2008, 70:668-676.

22. Qureshi S, Pyne J, Magruder K, Schulz P, Kunik M: The link between post-traumatic stress disorder and physical comorbidities: a systematic review. Psychiatr Q 2009, 80:87-97.

23. Boscarino JA: Posttraumatic stress disorder and physical illness: results from clinical and epidemiologic studies. Ann N Y Acad Sci 2004, 1032:141-153.

24. Baker DG, Nievergelt CM, O'Connor DT: Biomarkers of PTSD: neuropeptides and immune signaling. Neuropharmacology 2012, 62:663-673.

25. Pace TWW, Heim CM: A short review on the psychoneuroimmunology of posttraumatic stress disorder: from risk factors to medical comorbidities. Brain Behav Immun 2011, 25:6-13.

26. Sommershof $A$, Aichinger $H$, Engler $H$, Adenauer $H$, Catani $C$, Boneberg E-M, Elbert T, Groettrup M, Kolassa I-T: Substantial reduction of naïve and regulatory T cells following traumatic stress. Brain Behav Immun 2009, 23:1117-1124

27. Freier E, Weber CS, Nowottne U, Horn C, Bartels K, Meyer S, Hildebrandt Y, Luetkens T, Cao Y, Pabst C, Muzzulini J, Schnee B, Brunner-Weinzierl MC, Marangolo M, Bokemeyer C, Deter H-C, Atanackovic D: Decrease of CD4(+) FOXP3(+) T regulatory cells in the peripheral blood of human subjects undergoing a mental stressor. Psychoneuroendocrinology 2010, 35:663-673.

28. Schmidt D, Reber SO, Botteron C, Barth T, Peterlik D, Uschold N, Männel DN, Lechner A: Chronic psychosocial stress promotes systemic immune activation and the development of inflammatory Th cell responses. Brain Behav Immun 2010, 24:1097-1104.

29. World Health Organisation: ICD-10, International Statistical Classification of Diseases and Health Related Problems, 10th Revision. 1st edition. Geneva: World Health Organisation; 1992.

30. King LA, King DW, Leskin G, Foy DW: The Los Angeles symptom checklist a self report measure of posttraumatic stress disorder. Assessment 1995, 2:1-17.

31. Beck AT, Steer RA, Carbin MG: Psychometric properties of the Beck Depression Inventory: twenty-five years of evaluation. Clin Psychol Rev 1988, 8:77-100.

32. Spielberger CD, Gorsuch RL, Lushene RE: Manual for the State-Trait Anxiety Inventory. Palo Alto, CA: Consulting Psychologists Press; 1970.

33. Weinberg A, Song L-Y, Wilkening C, Sevin A, Blais B, Louzao R, Stein D, Defechereux P, Durand D, Riedel E, Raftery N, Jesser R, Brown B, Keller MF, Dickover R, McFarland E, Fenton T: Optimization and limitations of use of cryopreserved peripheral blood mononuclear cells for functional and phenotypic T-cell characterization. Clin Vaccine Immunol 2009, 16:1176-1186.

34. Van Hemelen D, Oude Elberink JNG, Heimweg J, van Oosterhout AJM, Nawijn MC: Cryopreservation does not alter the frequency of regulatory T cells in peripheral blood mononuclear cells. J Immunol Methods 2010, 353:138-140.

35. Spitzer C, Barnow S, Völzke H, Wallaschofski H, John U, Freyberger HJ, Löwe $\mathrm{B}$, Grabe HJ: Association of posttraumatic stress disorder with low-grade elevation of C-reactive protein: evidence from the general population. J Psychiatr Res 2010, 44:15-21.

36. Vaccarino V, Bremner JD, Afzal N, Veledar E, Goldberg J: Posttraumatic stress disorder is associated with higher c-reactive protein levels. J Am Coll Cardiol 2010, 55:A176.E1656. 
37. Kawamura N, Kim Y, Asukai N: Suppression of cellular immunity in men with a past history of posttraumatic stress disorder. Am J Psychiatry 2001, 158:484-486.

38. Vidović A, Vilibić M, Sabioncello A, Gotovac K, Rabatić S, Folnegović-Smalc V, Dekaris D: Circulating lymphocyte subsets, natural killer cell cytotoxicity, and components of hypothalamic-pituitary-adrenal axis in Croatian war veterans with posttraumatic stress disorder: cross-sectional study. Croat Med J 2007, 48:198-206.

39. Boscarino JA, Chang J: Higher abnormal leukocyte and lymphocyte counts 20 years after exposure to severe stress: research and clinical implications. Psychosom Med 1999, 61:378-386.

40. Ironson G, Wynings C, Schneiderman N, Baum A, Rodriguez M, Greenwood D, Benight C, Antoni M, LaPerriere A, Huang HS, Klimas N, Fletcher MA: Posttraumatic stress symptoms, intrusive thoughts, loss, and immune function after Hurricane Andrew. Psychosom Med 1997, 59:128-141.

41. Altemus M, Dhabhar FS, Yang R: Immune function in PTSD. Ann N Y Acad Sci 2006, 1071:167-183.

42. Wang J, loan-Facsinay A, van der Voort EIH, Huizinga TWJ, Toes REM: Transient expression of FOXP3 in human activated nonregulatory CD4+ T cells. Eur J Immunol 2007, 37:129-138.

43. Aerts NE, Dombrecht EJ, Ebo DG, Bridts CH, Stevens WJ, De Clerck LS: Activated T cells complicate the identification of regulatory $T$ cells in rheumatoid arthritis. Cell Immunol 2008, 251:109-115.

44. Baecher-Allan CM, Costantino CM, Cvetanovich GL, Ashley CW, Beriou G, Dominguez-Villar M, Hafler DA: CD2 costimulation reveals defective activity by human $\mathrm{CD} 4+\mathrm{CD} 25$ (hi) regulatory cells in patients with multiple sclerosis. J Immunol 2011, 186:3317-3326.

45. Jergović M, Tomičević M, Vidović A, Bendelja K, Savić A, Vojvoda V, Rac D, Lovrić-Čavar D, Rabatić S, Jovanovic T, Sabioncello A: Telomere shortening and immune activity in war veterans with posttraumatic stress disorder. Prog Neuropsychopharmacol Biol Psychiatry 2014, 54C:275-283.

46. Sakaguchi S, Wing K, Onishi Y, Prieto-martin P, Yamaguchi T: Regulatory T cells: how do they suppress immune responses? Int Immunol 2009, 21:1105-1111

47. Niedbala W, Wei X-Q, Cai B, Hueber AJ, Leung BP, Mclnnes IB, Liew FY: IL-35 is a novel cytokine with therapeutic effects against collagen-induced arthritis through the expansion of regulatory T cells and suppression of Th17 cells. Eur I Immunol 2007, 37:3021-3029.

48. Tiemessen MM, Jagger AL, Evans HG, Van Herwijnen MJC, John S, Taams LS: $\mathrm{CD} 4+\mathrm{CD} 25$ + Foxp3+ regulatory $T$ cells induce alternative activation of human monocytes/macrophages. Proc Natl Acad Sci U S A 2007, 104(49):19446-19451.

49. Zheng SG: Regulatory T cells vs Th17: differentiation of Th17 versus Treg, are the mutually exclusive? Am J Clin Exp Immunol 2013, 2:94-106.

50. Adalid-Peralta L, Fragoso G, Fleury A, Sciutto E: Mechanisms underlying the induction of regulatory $\mathrm{T}$ cells and its relevance in the adaptive immune response in parasitic infections. Int J Biol Sci 2011, 7(9):1412-1426.

51. Gotovac K, Sabioncello A, Rabatic S, Berki T, Dekaris D: Flow cytometric determination of glucocorticoid receptor (GCR) expression in lymphocyte subpopulations: lower quantity of GCR in patients with post-traumatic stress disorder (PTSD). Clin Exp Immunol 2003, 131:335-339.

52. Blake DD, Weathers FW, Nagy LM, Kaloupek DG, Gusman FD, Charney DS, Keane TM: The development of a clinician-administered PTSD scale. J Trauma Stress 1995, 8:75-90

53. Keane TM, Newman E, Orsillo SM: The assessment of military-related PTSD. In Assessing Psychological Trauma and PTSD. 1st edition. Edited by Wilson JP, Keane TM. New York: The Guilford Press; 1996:267-290.

doi:10.1186/1710-1492-10-43

Cite this article as: Jergović et al: Patients with posttraumatic stress disorder exhibit an altered phenotype of regulatory T cells. Allergy, Asthma \& Clinical Immunology 2014 10:43.

\section{Submit your next manuscript to BioMed Central and take full advantage of:}

- Convenient online submission

- Thorough peer review

- No space constraints or color figure charges

- Immediate publication on acceptance

- Inclusion in PubMed, CAS, Scopus and Google Scholar

- Research which is freely available for redistribution

Submit your manuscript at www.biomedcentral.com/submit 